\title{
3 Research Square \\ Bacterial and Fungal Co-infections with SARS-CoV-2 in Solid Organ Recipients, A Retrospective Study
}

\section{Mojtaba Shafiekhani}

Shiraz University of Medical Sciences

\section{Zahra Shekari}

Shiraz University of Medical Sciences

Arash Boorboor

Shiraz University of Medical Sciences

\section{Zahra Zare}

Shiraz University of Medical Sciences

\section{Sara Arabsheybani}

Shiraz University of Medical Sciences

Nazanin Azadeh ( $\square$ nazaninazadeh91@gmail.com )

Shiraz University of Medical Sciences https://orcid.org/0000-0002-5257-9638

\section{Research Article}

Keywords: Solid organ transplantation, COVID-19, co-infections

Posted Date: January 4th, 2022

DOI: https://doi.org/10.21203/rs.3.rs-244333/v2

License: (c) (i) This work is licensed under a Creative Commons Attribution 4.0 International License. Read Full License

Version of Record: A version of this preprint was published at Virology Journal on March 4th, 2022. See the published version at https://doi.org/10.1186/s12985-022-01763-9. 


\section{Abstract}

Background SARS-CoV-2, a novel corona virus, has caused clusters of fatal pneumonia worldwide. Immune compromised patients are among the high risk groups with poor prognosis of the disease. The presence of bacterial or fungal co-infections with SARS-CoV-2 is associated with increased mortality.

Methods The electronic data of the liver and kidney recipients, hospitalized in COVID-19 intensive care unit in an 8-month period in 2020 were retrospectively assessed. The documented bacterial or fungal infections alongside with outcome and risk factors were recorded and analyzed by binary logistic regression model and multivariate analyses.

Results Sixty-Six liver and kidney recipients were included this study. Twenty one percent of the patients had at least one episode of co-infection during their COVID-19 course. Bacterial and fungal co-infections contributed to a significantly higher mortality. Urine and sputum were the most common sites of pathogen isolation ( $45.45 \%$ and $36.36 \%$; respectively). The majority of infections were caused by vancomycin- resistant Enterococci (30\%). Escherichia coli stood in the next position with $23.3 \%$. Prior hospitalization and high does corticosteroid use were associated with co-infections $(p=0<0.001$ and $p=0.02$; respectively.)

Conclusions Bacterial and fungal co-infections with COVID-19 are more prevalent in solid organ recipients compared to the general population. Prior hospitalizations and use of broad-spectrum antimicrobial agents lead to emergence of multi-drug resistant pathogens in this susceptible patient population. Early detection and treatment of co-infections as well as antibiotic stewardship is recommended in solid organ recipients.

\section{Background}

Since December 2019, the world has faced a challenging infectious disease called "Coronavirus disease 2019 (COVID-19)". Since then, the highly contagious disease has caused financial and medical challenges and widespread lockdown throughout the globe (1). The rapidly spreading disease is caused by the severe acute respiratory syndrome coronavirus 2 (SARS-CoV-2), a novel strain of the coronaviruses (2). Although generally harmless, coronaviruses have previously gained notoriety for outbreaks of viral pneumonias including severe acute respiratory syndrome (SARS) and Middle East respiratory syndrome (MERS) (3). Since a few months after the emergence of the new disease, Iran has faced a challenging number of COVID-19 cases and mortality among the middle-eastern countries (4). Among the patients, solid organ transplant (SOT) recipients are a notable matter of concern. Receiving immunosuppressant poses the SOT patients to higher risk of developing symptomatic COVID-19 disease, compared to the normal population (5). A French study has reported a COVID-19 incidence of $5 \%$ in kidney recipients; while the incidence of the disease was $0.3 \%$ in the healthy population (6). The management of COVID-19 in SOT patients is especially complicated. Immunosuppressant doses should be high enough to maintain the intact function of the transplanted organ, and low enough to prevent the side effects and progression 
of the viral disease of COVID-19 (7). Another consideration in SOT recipients is the bacterial and fungal co-infections with SARS-COV-2. In Wuhan, a study reported $15 \%$ prevalence of secondary bacterial infections among the hospitalized patients; meanwhile, the non-survivor group had a considerably higher prevalence of bacterial co-infections, compared to the survivors ( $50 \%$ vs $1 \%$; respectively). In the study, immune dysregulation and prolonged hospitalization were among the risk factors associated with nosocomial infections in COVID-19 patients (8).

Considering the significant role of co-infections in management and prognosis of COVID-19 in SOT patients, this study was done on the SOT recipients, hospitalized due to COVID-19, in Shiraz Transplant center, Iran, as the main center of SOT in the Middle East. The prevalence, type, risk factors and prognosis of bacterial and fungal co-infections with SARS-COV-2 in SOT patients were assessed in the current study.

\section{Methods}

\section{Study Setting and Patients}

The study was designed as a retrospective observational analysis of all the SOT patients admitted in the COVID-19 ICU of Abu-Ali Sina Hospital of Shiraz University of Medical Sciences, Iran from March 2020 to October 2020. The 30-bedded COVID-19 ICU was founded since the beginning of the pandemy specializing for admission of SOT recipients. COVID-19 was diagnosed either by positive SARS-CoV-2 polymerase chain reaction (PCR) or by clinical symptoms with typical radiologic findings. Daily visits of patients was done by a multidisciplinary team consisting of a hepatobiliary surgeon, an infectious man, a nephrologist, an internist and a clinical pharmacist focusing on antiviral therapy, corticosteroid administration and managing the complications of the diseases.

\section{Data Collection}

The Demographic and laboratory data, microbiological results, medical interventions, disease outcome, length of mechanical ventilation, ICU and hospitalization and complications of COVID-19 were recorded and accessed from the available electronic documents of the patients. The documented bacterial and fungal infections were re-evaluated by the infectious men.

\section{Procedures and Definitions}

Nasopharyngeal and oral swabs were used to obtain samples from suspected COVID-19 patients. The samples were tested at a central laboratory using real-time reverse transcriptase PCR according to the WHO criteria (9). Based on the clinical and laboratory findings, microbiological cultures from either blood, urine, or sputum were taken. Chest X-ray or lung computed tomography (CT) were demanded for the patients with suspected pneumonia. Blood cultures were obtained by the standard procedure (10). The 
automats used were the BacT/ALERT 3D-automated blood culture system (bioMérieux, Durham, NC, USA) and the BACTEC FX (BD Diagnostic Systems, Sparks, MD, USA) (FX) for rapid microbial detection. Results were interpreted according to the clinical and laboratory standards institute (CLSI) guideline (11). An expert infectious man exploited the clinical guidelines of the centers for disease control (CDC) for diagnosis of bacterial and fungal infections (12).

Co-infection was defined by clinical signs and/or symptoms of bacterial or fungal infection alongside with detection of a pathogen by a diagnostic test.

The classification of infections was based on the CDC/NHSN surveillance classification of healthcareassociated infections and criteria for specific types of infections in the acute care setting (12). Sepsis diagnosis is based on Surviving sepsis campaign (13).

For each episode of infection, the symptoms, duration, site of infection, the isolated pathogens, prognosis and complications were recorded. Multidrug-resistant (MDR) and Extensive Drug Resistance (XDR) pathogens were defined in accordance with the Consensus Statement of the European Centre for Disease Prevention and Control and the American CDC evidence of infection (14).

\section{Statistical Analysis}

The statistical analyses were performed by statistical package for social sciences (SPSS Inc., Chicago, Illinois, USA) version 26.0. Descriptive statistics were presented as mean \pm SD and proportions as appropriate. Factors affecting infections were assessed by using binary logistic regression model and multivariate analyses. The Chi-square test or Fisher's exact test were used to compare the categorical data. The statistical significance level was set at $p<0.05$.

\section{Results}

During the duration of the study 97 adult and pediatric SOT recipients were admitted in the COVID-19 ICU, 68\% (66 patients) of whom had positive PCR for SARS-CoV-2 and the rest were diagnosed by clinical and radiologic findings. Three of the patients aged less than 18 years old. The 31 patients with negative PCR were excluded from the study. The patient population consisted of 32 liver and 34 kidney recipients. The mean \pm SD age of the patients was $55.22 \pm 9.91$ years. The majority of the patients were male (59.1\% of patients). The demographic, comorbidity and disease data of the patients are presented in Table 1.

\section{Table 1}

Demographic and clinical characteristics of solid organ recipients with Positive PCR for SARS-CoV-2 $(\mathrm{N}=66)$. 


\begin{tabular}{|c|c|c|c|c|c|}
\hline \multicolumn{2}{|c|}{ Patient/Disease characteristics } & $\begin{array}{l}\text { Total } \\
\text { patients } \\
(n=66)\end{array}$ & $\begin{array}{l}\text { Co-infected } \\
\text { group } \\
(n=14)\end{array}$ & $\begin{array}{l}\text { The non-co- } \\
\text { infected } \\
\text { group }(n=52)\end{array}$ & $\begin{array}{l}\mathrm{P} \text { - } \\
\text { value }\end{array}$ \\
\hline \multicolumn{2}{|l|}{ Mean age (Year) } & $55.22 \pm 9.91$ & $59.1 \pm 11.2$ & $54.01 \pm 8.89$ & 0.61 \\
\hline \multirow[t]{2}{*}{ Sex } & Male & 39 & 11 & 28 & 0.75 \\
\hline & Female & 27 & 3 & 24 & \\
\hline \multirow{2}{*}{$\begin{array}{l}\text { Transplanted } \\
\text { organ }\end{array}$} & Liver & 32 & 9 & 23 & 0.89 \\
\hline & Kidney & 34 & 5 & 29 & 0.55 \\
\hline \multirow{5}{*}{$\begin{array}{l}\text { Comorbid } \\
\text { Disease }\end{array}$} & Diabetes & 22 & 11 & 11 & \multirow{5}{*}{$\begin{array}{l}p> \\
0.05\end{array}$} \\
\hline & Hypertension & 31 & 7 & 24 & \\
\hline & & 37 & 11 & 20 & \\
\hline & $\begin{array}{l}\text { Ischemic heart } \\
\text { disease }\end{array}$ & 1 & 1 & 0 & \\
\hline & $\begin{array}{l}\text { Chronic obstructive } \\
\text { Pulmonary } \\
\text { disease/Asthma }\end{array}$ & & & & \\
\hline \multirow{2}{*}{$\begin{array}{l}\text { Time After } \\
\text { Transplant } \\
\text { (months) }\end{array}$} & $<6$ months & 38 & 11 & 27 & \multirow[t]{2}{*}{0.11} \\
\hline & $>6$ months & 28 & 3 & 25 & \\
\hline \multirow[t]{3}{*}{ Oxygen Therapy } & Nasal Cannula & 41 & 9 & 32 & \multirow[t]{3}{*}{0.06} \\
\hline & Mechanical & 18 & 5 & 13 & \\
\hline & None & 7 & 0 & 7 & \\
\hline \multicolumn{2}{|l|}{ WBC $\left(\times 10^{3} / L\right)$} & $12.21 \pm 4.31$ & $14.69 \pm 7.01$ & $11.5 \pm 5.91$ & 0.49 \\
\hline \multicolumn{2}{|l|}{$\mathrm{CRP}(\mathrm{mg} / \mathrm{L})$} & $75 \pm 21$ & $122 \pm 31$ & $48 \pm 22$ & 0.04 \\
\hline \multicolumn{2}{|l|}{$\mathrm{LDH}(\mathrm{U} / \mathrm{L})$} & $241 \pm 89$ & $256 \pm 91$ & $213 \pm 101$ & 0.75 \\
\hline \multicolumn{2}{|l|}{$\begin{array}{l}\text { Length of } \\
\text { hospitalization } \\
\text { (day) }\end{array}$} & - & $17.01 \pm 2.11$ & $12.24 \pm 3.71$ & 0.22 \\
\hline \multicolumn{2}{|l|}{$\begin{array}{l}\text { Length of } \\
\text { mechanical } \\
\text { ventilation (day) }\end{array}$} & - & $11 \pm 4$ & $8 \pm 4$ & 0.17 \\
\hline \multicolumn{2}{|l|}{ Mortality } & 6 & 5 & 1 & 0.01 \\
\hline \multicolumn{2}{|l|}{ Rejection } & 1 & 0 & 1 & 0.91 \\
\hline \multicolumn{2}{|l|}{ Length of ICU } & - & $19.01 \pm 10.00$ & $8.90 \pm 4.02$ & $\mathrm{p}<$ \\
\hline
\end{tabular}


Abbreviations: CRP: C - reactive protein, ICU: Intensive care unit, LDH: Lactate dehydrogenase, WBC: White Blood Cell

A total number of 14 patients (21.2\%) had an overall 22 episodes of bacterial or fungal co-infections with SARS-CoV-2. Type of the transplanted organ (kidney vs liver), comorbid diseases, need for oxygen therapy and time passed from the transplantation were not significantly associated with increased risk of coinfections. The co-infected group had a significantly higher C-reactive protein (CRP) compared to the noninfected ones $(122 \pm 31 \mathrm{mg} / \mathrm{L}$ vs $48 \pm 22 \mathrm{mg} / \mathrm{L}$; respectively $p=0.04)$, whereas the white blood cell (WBC) count was not associated with bacterial and fungal co-infection $\left(14.69 \pm 7.0110^{3} / \mu \mathrm{L}\right.$ in the co-infected group vs $11.5 \pm 5.9110^{3} / \mu \mathrm{L}$ in the non-co-infected group, $p=0.49$ ). Among the 14 patients with coinfections, 5 individuals eventually passed away (35.7\%), while 1 out of the 52 patients in the non-coinfected group died during the hospital course (1.9\%). The presence of bacterial and fungal co-infections with SARS-CoV-2 was significantly associated with mortality $(p=0.01)$. A significantly longer ICU stay was recorded in the co-infected group compared to the non-co-infected patients ( $19 \pm 10$ days vs $8 \pm 4$ days; respectively, $p<0.0001)$.

Urine and sputum constituted the majority sites of pathogen isolation ( $45.4 \%$ and $36.3 \%$ of infectious sources; respectively). Enterococcus Spp, Escherchia Coli and Candida non-albicans were the most common isolated pathogens from the patients (30\%, $23.3 \%$ and $13.3 \%$; respectively). Among the infections, 9 episodes were co-infections with 2 pathogens (39.1\%). A high prevalence of antibioticresistant bacterial strains was detected in the study. Among the 9 isolated Enterococci, 5 were of the vancomycin-resistent (VRE) type (55.5\%). Both the 2 isolated Staphylococci spp were Methicillin-resistant Staphylococcus aureus (MRSA) and 6 of the 9 isolated Entrobacteriaceae species were Carbapenemresistant Enterobacteriaceae (CRE) (66.66\%). The infectious sources and isolated pathogens are demonstrated in Table 2.

\section{Table 2}

Isolated pathogens and site of infections among solid organ recipients affected with COVID-19. 


\begin{tabular}{|lll|}
\hline Infection Characteristics & & Number/Percent \\
\hline Site of pathogen isolation (n=22) & Urine & $10(45.45 \%)$ \\
& Sputum & $8(36.36 \%)$ \\
& Abdominal/Pleural fluid & $2(9.09 \%)$ \\
& Wound & $1(4.54 \%)$ \\
& Blood & $1(4.54 \%)$ \\
& & \\
Isolated Microorganisms (n=23) & Enterococcus spp. & $9(30 \%)$ \\
& Escherichia coli & $7(23.3 \%)$ \\
& Candida Non-albicans & $4(13.3 \%)$ \\
& Candida Albicans & $1(3.3 \%)$ \\
& Klebsiella spp. & $3(10 \%)$ \\
& Pseudomonas spp. & $2(6.6 \%)$ \\
& Acinetobacter spp. & $2(6.6 \%)$ \\
& MRs & $2(6.6 \%)$ \\
& & \\
\hline
\end{tabular}

Univariate regression analysis showed that diabetes mellitus, high dose of corticosteroids, history of hospitalization prior to COVID-19 and the length of hospital stay were the risk factors associated with bacterial or fungal co-infections with SARS-CoV-2. The multivariate analysis showed that among the mentioned risk factors, high dose of corticosteroids and prior hospitalization were the associated risk factors of bacterial and fungal co-infections with COVID-19. Table 3. Shows the results of the regression analysis.

Table 3

Univariate and multivariate analysis for the risk of bacterial and fungal co-infections among solid organ recipients affected with COVID-19. 


\begin{tabular}{|lll|}
\hline Variables & $\begin{array}{l}\mathrm{OR}(95 \% \mathrm{Cl}) \\
(\mathrm{P}-\mathrm{value}) \text { Univariate }\end{array}$ & $\begin{array}{l}\mathrm{OR}(95 \% \mathrm{Cl}) \\
(\mathrm{P}-\mathrm{value}) \text { Multivariate }\end{array}$ \\
\hline Sex & $1.21(0.98-1.02)(.78)$ & - \\
\hline Age & $0.91(.77-2.29)(.92)$ & - \\
\hline Kidney transplantation & $1.01(.23-5.42)(0.22)$ & - \\
\hline Liver transplantation & $2.29(.11-4.98)(0.33)$ & - \\
\hline Tacrolimus Level & $0.21(-.01 .1-2.92)(.91)$ & - \\
\hline High dose of corticosteroids & $5.65(2.44-7.91)(0.03)$ & $3.91(2.02-6.90)(0.02)$ \\
\hline Diabetes mellitus & $4.94(3.41-6.98)(<0.001)$ & $2.11(0.96-3.41)(0.79)$ \\
\hline Hypertension & $2.20(0.9-23.94)(0.76)$ & - \\
\hline Length of hospitalization & $1.1(1.3-1.56)(0.03)$ & $2.19(0.81-6.71)(0.79)$ \\
\hline Prior hospitalization before COVID-19 & $2.94(2.77-6.79)(0.02)$ & $3.66(2.89-7.99)(<0.001)$ \\
\hline
\end{tabular}

\section{Discussion}

Immunocompromised patients are among the high risk groups to be infected with the novel SARS-CoV-2 virus. The immunocompromised, more frequently tend to be admitted in the COVID-19 ICUs, more frequently end up with mechanical ventilation and have higher mortality rates (15). In a New York City study of 90 SOT patients, the mortality rate of COVID-19 was reported to be $18 \%$, significantly higher than the normal population (16). Efforts to maintain the intact function of the transplanted organ and concurrent reduction of the immune suppression dose to prevent severe viral disease, makes the management of COVID-19 in SOT patients remarkably challenging.

Due to immunosuppressive therapy, infections are already a frequent hazard in management of SOT patients. Bacteria are the most common pathogens causing infections after SOT, particularly in the early post-transplantation period $(17,18)$. Multiple previous hospitalizations, invasive interventions and prior antibiotic use makes the SOT patients a susceptible population to colonize nosocomial and antibiotic resistant pathogens including MRSA, VRE and resistant gram negative bacilli (19). On the other hand, community acquired infections may cause severe diseases in SOT patients, for instance bacterial or fungal superinfections exacerbate the common viral respiratory diseases in this vulnerable patient population (20).

Co-infections in general COVID-19 patients are not a frequent event, thus routine administration of antimicrobial agents is not recommended (21). Bacterial and fungal infections are reported to co-exist with SARS-CoV-2 to be $8 \%$ among 806 patients integrated in a meta-analysis of the available worldwide studies (22). In another meta-analysis of 3834 COVID-19 patients, the prevalence of co-infections was 
calculated to be 7\%, in accordance with the previous study. In the study, Mycoplasma pneumonia, Pseudomonas aeruginosa and Haemophilus influenza were the most common organisms to cause secondary bacterial infections (23). The superinfections were reported to occur as high as $44 \%$ in critically ill ICU patients (24). Up to this date, few comprehensive studies of co-infections in COVID-19 SOT patients have been conducted. In this study we collected the clinical data of the 66 hospitalized SOT patients diagnosed with COVID-19 by positive SARS-CoV-2 PCR. The prevalence of bacterial or fungal infections was $21.2 \%$ among our patient population which was as predicted, higher than non-SOT COVID-19 patients. In a French report of COVID-19 course in kidney transplant recipients, $23.5 \%$ of the patients had a secondary bacterial infection (25). Patients with superinfections are at a higher risk of requiring ICU care and mechanical ventilation (26). The incidence of bacterial co-infections in newly admitted COVID19 patients is relatively low (27). However, according to our study results, as ICU stay prolongs, the risk for co-infections increases. Furthermore, the need for mechanical ventilation increases the risk to acquire hospital-associated secondary pneumonia (28). In the current analysis, prior hospitalization and high dose corticosteroid dose were associated with increased risk of co-infection in SOT patients. In a previous study, older age was stated to be associated with more prevalent co-infections (29). Nori et, al. have reported that $100 \%$ of the patients with MDR co-infections had received prior antibiotics (30).

Antimicrobial-resistant pathogens were frequent among our positive cultures, warning for an attentive antibiotic stewardship and avoiding empiric antibiotic prescription. Due to prior hospitalizations as a consequence of transplantation complications and receiving broad-spectrum antimicrobial agents, the high prevalence of MDR pathogens in SOT patients is a logical assumption $(31,32)$. Of the MDR pathogens, VRE is of special concern as VRE infections contribute to various complications and 2-fold increased mortality of the liver transplantation patients (33). The prevalence of VRE is differently reported worldwide and has high prevalence in some areas (31). In our study, the most common isolated bacteria in COVID-19 SOT patients were VRE species. The majority of VRE infections occur in pre-colonized patients (34). In a previous evaluation of pre-transplant patients in our center $9 \%$ were colonized with VRE (35). Furthermore, the majority of the isolated Candida species were of the non-albicans type (80\%). The emergence of non-albicans Candida species is a global phenomenon, as the use of azole antifungals is being frequently applied (36). In the field of SOT, azoles are regularly prescribed as an anti-fungal prophylaxis. Therefore, an increasing trend in infections with non-albicans Candida rather than Candida alibicans is being observed (34).

Altogether, the most common type of secondary infection in COVID-19 patients is pneumonia, with blood stream and urinary tract infections standing at the next positions. (26). In the current study, urinary tract and sputum were the most common sites of pathogen isolation in the SOT patients, similar to the general COVID-19 patients. Ventilator-associated pneumonia was the most common co-infection in a surveillance of 52 SOT patients by Roberts et, al (37). Superinfections should carefully be paid attention to, as they can be the terminal event resulting in death (38). Secondary bacterial infections were detected in $50 \%$ of the COVID-19 patients who had died, according to Zhou et, al (8). Martins-Filho et al, have reported a 2.5 fold mortality rate of COVID-19 in presence of co-infections (39). In our study, the existence of bacterial 
and fungal co-infections contributed to a significantly high mortality rate (35.7\%), while a small proportion of the non-co-infected group passed away (0.019\%).

Differentiating COVID-19 progression and a secondary bacterial infection is challenging, as the inflammatory markers might be elevated in absence of co-infections. In our patient population, the coinfected group had a dramatically higher mean CRP level. CRP is usually elevated in the COVID-19 patients as a result of ongoing inflammation. In an extensive Chinese review, $60.7 \%$ of the patients had high blood CRP level (40). Furthermore, a higher CRP level is associated with a more severe COVID-19 pneumonia and is an early predictive index of disease severity $(41,42)$. Procalcitonin (PCT), the precursor of the thyroid hormone calcitonin, is produced by extra-thyroidal tissues during inflammatory response to bacterial components (43) . In non-bacterial inflammations, PCT is either in normal range or slightly elevated, which makes it a more desirable biomarker rather than CRP to predict bacterial co-infection (44). One limitation of our study was, due to its retrospective nature, the scarce measurement and limited data of PCT levels in patients. Another limitation of our study was the limited number of patients, since it was a single center experience. Further studies of COVID-19 and co-infections in SOT patients are encouraged.

\section{Conclusions}

SOT patients are a vulnerable population to be infected with SARS-CoV-2. Prior hospitalizations and immunosuppressive therapy makes them a susceptible group to contact bacterial or fungal infections during COVID-19 course. Although bacterial and fungal co-infection prevalence is higher in SOT patients, precise antibiotic stewardship is still recommended to prevent the emergence of multi-drug resistant organisms.

\section{Declarations}

\section{Ethics approval and consent to participate}

The study involving access to human participant's medical records was approved by the ethics committee of the department of Transplantation at Shiraz University of Medical Sciences. Written consent was obtained from the patients.

\section{Consent for publication}

Written informed consent was obtained from the all the patients for publication of their personal and clinical details to be published in the study. The patients provided a written consent regarding publishing their disease information in the article. A copy of the written consent is available for review by the Editor of this journal.

\section{Availability of data and materials}




\section{Competing interests}

The authors declare they have no competing interests.

\section{Funding}

No funding was applied for this study.

\section{Authors' contributions}

MSH was the clinical pharmacologist of the ward. SA was the infectious man who visited the patients. $\mathrm{ZZ}, \mathrm{AB}$ and $\mathrm{ZSH}$ gathered the information and analyzed the data. NA conceived the paper and wrote it. All authors reviewed the paper and agreed to be accountable for all aspects of the work in ensuring that questions related to the accuracy or integrity of any part of the work are appropriately investigated and resolved.

\section{Acknowledgements}

Not Applicable.

\section{References}

1. Gopalan HS, Misra A. COVID-19 pandemic and challenges for socio-economic issues, healthcare and national programs in India. Diabetes \& Metabolic Syndrome: Clinical Research \& Reviews. 2020.

2. Hu B, Guo H, Zhou P, Shi Z-L. Characteristics of SARS-CoV-2 and COVID-19. Nature Reviews Microbiology. 2020:1-14.

3. Yin Y, Wunderink RG. MERS, SARS and other coronaviruses as causes of pneumonia. Respirology. 2018;23(2):130-7.

4. Abdi M. Coronavirus disease 2019 (COVID-19) outbreak in Iran: Actions and problems. Infection Control \& Hospital Epidemiology. 2020;41(6):754-5.

5. Zhang H, Dai H, Xie X. Solid organ transplantation during the COVID-19 pandemic. Frontiers in Immunology. 2020;11:1392.

6. Elias M, Pievani D, Randoux C, Louis K, Denis B, Delion A, et al. COVID-19 infection in kidney transplant recipients: disease incidence and clinical outcomes. Journal of the American Society of Nephrology. 2020;31(10):2413-23. 
7. Mirjalili M, Shafiekhani M, Vazin A. Coronavirus disease 2019 (COVID-19) and transplantation: Pharmacotherapeutic management of immunosuppression regimen. Therapeutics and Clinical Risk Management. 2020;16:617.

8. Zhou F, Yu T, Du R, Fan G, Liu Y, Liu Z, et al. Clinical course and risk factors for mortality of adult inpatients with COVID-19 in Wuhan, China: a retrospective cohort study. The lancet. 2020;395(10229):1054-62.

9. Corman VM, Landt O, Kaiser M, Molenkamp R, Meijer A, Chu DK, et al. Detection of 2019 novel coronavirus (2019-nCoV) by real-time RT-PCR. Eurosurveillance. 2020;25(3):2000045.

10. Kirn T, Weinstein M. Update on blood cultures: how to obtain, process, report, and interpret. Clinical Microbiology and Infection. 2013;19(6):513-20.

11. Wayne P. Clinical and laboratory standards institute. Performance standards for antimicrobial susceptibility testing. 2011.

12. Horan TC, Andrus M, Dudeck MA. CDC/NHSN surveillance definition of health care-associated infection and criteria for specific types of infections in the acute care setting. American journal of infection control. 2008;36(5):309-32.

13. Levy MM, Evans LE, Rhodes A. The surviving sepsis campaign bundle: 2018 update. Intensive care medicine. 2018;44(6):925-8.

14. Martin-Loeches I, Torres A, Rinaudo M, Terraneo S, de Rosa F, Ramirez P, et al. Resistance patterns and outcomes in intensive care unit (ICU)-acquired pneumonia. Validation of European Centre for Disease Prevention and Control (ECDC) and the Centers for Disease Control and Prevention (CDC) classification of multidrug resistant organisms. Journal of Infection. 2015;70(3):213-22.

15. Fung M, Babik JM. COVID-19 in Immunocompromised Hosts: What We Know So Far. Clinical Infectious Diseases. 2020.

16. Pereira MR, Mohan S, Cohen DJ, Husain SA, Dube GK, Ratner LE, et al. COVID-19 in solid organ transplant recipients: Initial report from the US epicenter. American Journal of Transplantation. 2020.

17. Garzoni C. Multiply resistant Gram-positive bacteria methicillin-resistant, vancomycin-intermediate and vancomycin-resistant Staphylococcus aureus (MRSA, VISA, VRSA) in solid organ transplant recipients. American journal of transplantation. 2009;9(s4).

18. Shafiekhani M, Mirjalili M, Vazin A. Prevalence, Risk Factors And Treatment Of The Most Common Gram-Negative Bacterial Infections In Liver Transplant Recipients: A Review. Infection and drug resistance. 2019;12:3485.

19. Delden Cv, Blumberg E. Multidrug resistant gram-negative bacteria in solid organ transplant recipients. American Journal of Transplantation. 2009;9(s4).

20. Fishman JA. Infection in Solid-Organ Transplant Recipients. New England Journal of Medicine. 2007;357(25):2601-14.

21. Youngs J, Wyncoll D, Hopkins P, Arnold A, Ball J, Bicanic T. Improving antibiotic stewardship in COVID-19: Bacterial co-infection is less common than with influenza. The Journal of Infection. 2020. 
22. Rawson TM, Moore LSP, Zhu N, Ranganathan N, Skolimowska K, Gilchrist M, et al. Bacterial and Fungal Coinfection in Individuals With Coronavirus: A Rapid Review To Support COVID-19 Antimicrobial Prescribing. Clinical Infectious Diseases. 2020;71(9):2459-68.

23. Lansbury L, Lim B, Baskaran V, Lim WS. Co-infections in people with COVID-19: a systematic review and meta-analysis. Journal of Infection. 2020;81(2):266-75.

24. Chen X, Zhao B, Qu Y, Chen Y, Xiong J, Feng Y, et al. Detectable serum SARS-CoV-2 viral load (RNAaemia) is closely correlated with drastically elevated interleukin 6 (IL-6) level in critically ill COVID-19 patients. Clinical Infectious Diseases. 2020.

25. Caillard S, Anglicheau D, Matignon M, Durrbach A, Greze C, Frimat L, et al. An initial report from the French SOT COVID Registry suggests high mortality due to Covid-19 in recipients of kidney transplants. Kidney international. 2020;98(6):1549-58.

26. Kewan T, Chawla S, Saleem T, Afzal S, Saand A, Alqaisi S. SUPERINFECTIONS IN PATIENTS INFECTED WITH COVID-19: A SINGLE-CENTER EXPERIENCE. Chest. 2020;158(4):A350-A.

27. Adler H, Ball R, Fisher M, Mortimer K, Vardhan MS. Low rate of bacterial co-infection in patients with COVID-19. The Lancet Microbe. 2020;1(2):e62.

28. Cox MJ, Loman N, Bogaert D, O'Grady J. Co-infections: potentially lethal and unexplored in COVID-19. The Lancet Microbe. 2020;1(1):e11.

29. Goncalves Mendes Neto A, Lo KB, Wattoo A, Salacup G, Pelayo J, DeJoy III R, et al. Bacterial infections and patterns of antibiotic use in patients with COVID-19. Journal of medical virology. 2020.

30. Nori P, Cowman K, Chen V, Bartash R, Szymczak W, Madaline T, et al. Bacterial and fungal coinfections in COVID-19 patients hospitalized during the New York City pandemic surge. Infection Control \& Hospital Epidemiology. 2020;42(1):84-8.

31. Cervera C, Van Delden C, Gavaldà J, Welte T, Akova M, Carratalà J, et al. Multidrug-resistant bacteria in solid organ transplant recipients. Clinical Microbiology and Infection. 2014;20:49-73.

32. Shafiekhani M, Karimzadeh I, Nikeghbalian S, Firoozifar M, Pouladfar G, Vazin A. Comparison of Ceftizoxime Plus Ampicillin-Sulbactam versus Gentamicin Plus Ampicillin-Sulbactam in the Prevention of Post-Transplant Early Bacterial Infections in Liver Transplant Recipients: A Randomized Controlled Trial. Infection and drug resistance. 2020;13:89.

33. Russell D, Flood A, Zaroda T, Acosta C, Riley M, Busuttil R, et al. Outcomes of colonization with MRSA and VRE among liver transplant candidates and recipients. American Journal of Transplantation. 2008;8(8):1737-43.

34. Cruciani M, Mengoli C, Malena M, Bosco O, Serpelloni G, Grossi P. Antifungal prophylaxis in liver transplant patients: A systematic review and meta-analysis. Liver Transplantation. 2006;12(5):8508.

35. Jafarpour Z, Pouladfar G, Malek Hosseini SA, Firoozifar M, Jafari P. Bacterial infections in the early period after liver transplantation in adults: A prospective single-center cohort study. Microbiology and Immunology. 2020;64(6):407-15. 
36. Whaley SG, Berkow EL, Rybak JM, Nishimoto AT, Barker KS, Rogers PD. Azole Antifungal Resistance in Candida albicans and Emerging Non-albicans Candida Species. Frontiers in Microbiology. 2017;7(2173).

37. Roberts MB, Izzy S, Tahir Z, Al Jarrah A, Fishman JA, El Khoury J. COVID-19 in solid organ transplant recipients: Dynamics of disease progression and inflammatory markers in ICU and non-ICU admitted patients. Transplant Infectious Disease. 2020;22(5):e13407.

38. Clancy CJ, Nguyen MH. Coronavirus Disease 2019, Superinfections, and Antimicrobial Development: What Can We Expect? Clinical Infectious Diseases. 2020;71(10):2736-43.

39. Martins-Filho PR, Tavares CSS, Santos VS. Factors associated with mortality in patients with COVID19. A quantitative evidence synthesis of clinical and laboratory data. European journal of internal medicine. 2020;76:97-9.

40. Guan W-J, Ni Z-Y, Hu Y, Liang W-H, Ou C-Q, He J-X, et al. Clinical Characteristics of Coronavirus Disease 2019 in China. N Engl J Med. 2020;382(18):1708-20.

41. Chen W, Zheng KI, Liu S, Yan Z, Xu C, Qiao Z. Plasma CRP level is positively associated with the severity of COVID-19. Annals of clinical microbiology and antimicrobials. 2020;19(1):18.

42. Tan C, Huang Y, Shi F, Tan K, Ma Q, Chen Y, et al. C-reactive protein correlates with computed tomographic findings and predicts severe COVID-19 early. Journal of medical virology. 2020;92(7):856-62.

43. Ponti G, Maccaferri M, Ruini C, Tomasi A, Ozben T. Biomarkers associated with COVID-19 disease progression. Critical reviews in clinical laboratory sciences. 2020;57(6):389-99.

44. Delevaux I, Andre M, Colombier M, Albuisson E, Meylheuc F, Bègue R, et al. Can procalcitonin measurement help in differentiating between bacterial infection and other kinds of inflammatory processes? Annals of the rheumatic diseases. 2003;62(4):337-40. 